\title{
EXTRA CORONARY ATHEROSCLEROSIS IN PATIENTS WITH DOCUMENTED CORONARY ARTERY DISEASE
}

\author{
964 \\ *Wael Refaie and ${ }^{*}$ Salah Tantawy \\ Trom \\ ${ }^{*}$ Cardiology and ${ }^{* \star}$ Radiology Department \\ MansouraFaculty of Medicine
}

\begin{abstract}
Background : Searching for extracoronary atherosclerosis in patients with documented coronary artery disease (CAD) is essential because the detrimental link between cardiac, renal, carotid and peripheral arterial diseases are common and atherosclerosis is well known as a polydistrectual disease Objectives: To identify the prevalence of renal artery stenosis (RAS), carotid artery atherosclerosis (CAA) and/or peripheral arterial disease (PAD) in patients with proven $\mathrm{CAD}$ and to illustrate their risk factors and to clarify the clinical, non invasive maneuvers for their diagnosis as most of them are either silent or minimally symptomatizing. Study design: Cross section study. Patients and methods: One hundred and thirty six cases (92
\end{abstract}

males and 44 females) with mean age of $66.2 \pm 6.8$ years, who were subjected in the preceding year to coronary angiography for acute coronary syndrome and were coming for follow up. Clinical examination stressing on some atherosclerosis risk factors (blood pressure, blood glucose and serum lipids), symptoms and signs that may be specific for ischemia in different vascular territories, intermittent claudication, abdominal bruit, carotid bruit, ankle brachial index $(A B I)$, serum potassium, serum creatinine. Electrocardiography, echocardiography, Duplex ultrasonography for carotid, renal and lower limb arteries were stressed upon. The examined cases were then grouped into those with either RAS, CAA, PAD versus cases without extracoronary involvement. 
Results: Significant RAS (Duplex US scan) was detected in $33.82 \%$, CAA in $29.41 \%$, PAD in $27.94 \%$ and in only $8.82 \%$ no significant extracoronary stenosis was detected. Significant high plasma glucose and smoking in PAD, while hypertension and dyslipidemia in RAS. Male gender and increased waist circumference were significantly higher in CAA and significant lowering of $A B I$ in $P A D$. Conclusion: Atherosclerosis involving extracoronary territories is prevailing in patients with documented CAD and screening by US duplex is mandatory to patients undergoing or had undergone coronary interventions.

Key word: extracoronary atherosclerosis, coronary artery disease.

\section{INTRODUCTION}

Atherosclerosis is a diffuse disease, though it affects certain regions of the vascular bed preferentially (1). In line with aging population, the prevalence of $C A D$, $P A D, C A A$ is increasing. Poly vascular atherosclerosis (PVA) existing in several territories usually has adverse effects on cardiovascular morbidities (2).

Searching for extracoronary ath- erosclerosis in patients with proven CAD is essential because the detrimental link between cardiac and renal pathology in RAS is well documented (3).

Presence and severity of incidental RAS is an independent predictor of morbidity and mortality in atherosclerotic patients regardless of the mode of treatment of $\operatorname{CAD}(1,4)$. Tobe and associates (2007) (5), defined RAS as narrowing of the lumen of renal artery $\geq 50 \%$ while atherosclerotic renovascular disease (ARVD) as a combination of RAS and renal ischemia.

RAS is not only a cause of accelerated, resistant HTN and a leading cause of renal impairment but according to Tami et al (1995) (6) may be a cause of unstability of CAD and crescendo angina pectoris, CVD and flash pulmonary oedema.

In the past, RAS was under recognized and under diagnosed. With improving noninvasive imaging techniques, the diagnosis is currently more frequently established (7). Diagnosis of RAS is necessary as early as possible because meaningful recovery of kidney function is limited 
once renal fibrosis is established (8). Gupta and associates (2010) (9) advised early recognition and management of RAS.

Many methods are of help in identifying the magnitude and location of the vascular territories involved in patients with CAD. Xie and coworkers (2012) (10) investigated the relationship between ankle brachial index $(A B I)$ and severity of ARAS and found that $A B I$ is a valuable predictive index of midrange to severe ARAS. YY and coworkers (2010) (11) concluded that renal duplex scanning (RDS) might still be the diagnostic procedure of choice for screening patients for ARAS.

\section{Aims:}

It was aimed to identify the prevalence of renal artery stenosis (RAS), carotid artery atherosclerosis (CAA) and/or peripheral artery disease (PAD) in patients with proven CAD and to illustrate their risk factors. Also to clarify the clinical, non invasive maneuvers for their diagnosis as most of them are either silent or minimally symptomatizing.

Design : Cross- section study.

\section{SUBJECTS AND METHODS}

One hundred and thirty six cases (92males and 44 females) with mean age of $66.2 \pm 6.8$ years, who had undergone during the preceding year coronary angiography with stenting or CABG for acute coronary syndrome and were coming for follow up with no specific symptoms which were attributed to their CAD state. Full clinical examination was done with special stress on symptoms and signs suggestive of vascular ischemia in other extracoronary vascular territories, including symptoms and signs of PAD (intermittent claudication, cold limbs, femoral bruit, dystrophic changes. Hypertension and its severity as defined by the Joint National Committee 2003 (JNC 7) (12) was stressed upon; abdominal bruit, captopril induced rise of serum creatinine, flash pulmonary oedema, hypokalemia. Giddiness, dizziness, transient ischemic attacks (TIA), carotid bruit and CNS examination were stressed upon. The study protocol was approved by the cardiology ethical committee and informed consents were obtained.

ABls were measured according to the method recommended by the American Heart Association, using

MANSOURA MEDICAL JOURNAL 
ABI form device (VP 1000 Colin, Komaki, Japan) in both arms and ankles using an Oscillo metric method measuring the systolic BP (Xie et al 2012). Fasting plasma glucose, post $75 \mathrm{gm}$ glucose challenge tests on two occasions was carried out together with lipogram. The diagnosis of DM, IFG, IGT were assessed according to the recommendation of the ADA (1998) (13). The criteria for dyslipidemia were according to the National Cholesterol Education Program (1993) (14).

- 12 lead ECG for evidences of CAD, ischemia, ventricular hypertrophy, arrhythmias

- Echocardiography for evidence of diastolic dysfunction using transmitral Doppler flow and graded as mild (grade 1; impaired relaxation, reversed E/A ratio), moderate (grade 2; pseudonormal decrease deceleration time), severe (restrictive pattern). Systolic dysfunction stressing on Ejection Fraction (EF) and Fibrous Shortening (FS) and LVH.

Duplex scanning of the carotid arteries were undertaken where the carotid arteries were examined in both transverse and sagital planes.
Four Doppler variables were considered as reliable predictors for the presence and severity of carotid vascular disease; peak systolic velocity (PSV), end diastolic velocity (EDV), spectral broadening, peak systolic velocity ratio; which is the peak systolic velocity in the internal carotid artery divided by the peak systolic velocity in the common carotid

Renal duplex (RD); after a minimum of 6 hours fasting and following a three day at least of low fibre diet and without smoking. RD were performed utilizing the anterior, antrolateral and lumber approach to examine the kidney, main renal artery and its branches as well as intrarenal flow by senior expert sonographer who was blinded to patient clinical data and utilizing the machine Toshiba SAL-270. The presence of any of the following six abnormalities were considered indicative for the presence of RAS according to Soulez et al (2000) (15).

- Direct visualization of stenosis in the mean RA or its branches with combined B- mode and colour Doppler ultrasound.

- Peak systolic velocity in renal artery more than $100 \mathrm{~cm} / \mathrm{sec}$

- Turbulent flow in the post ste- 
notic area.

- Renal resistance index more than 0.68 (peak systolic velocity- end diastolic velocity/ peak systolic velocity * 100) (5).

- A change in the renal resistance index greater than 5\% between right and left mean renal artery.

Duplex scanning of the arteries of the lower limbs were scanned with higher frequency transducer at the origin of the profunda femories, superfacial femoral artery, popliteal and proximal tibial arteries.

Statistical analysis: was performed by using the statistical package for social science program (SPSS) version "16". The qualitative data were presented as frequency and percentages. The quantitative data were examined by using Kalmogrov-Smirnov test to test for normal distribution of the data and when parametric, expressed as mean and standard deviation. Student $t$ test was used, to test for difference in normally distributed quantative data between the two groups. MannWhitney- $\mu$ test was used for comparison between two groups when data are not normally distributed. Signifi- cance was considered when $P$ value less than 0.05

\section{RESULTS}

After clinical examination and duplex scanning, the examined cases were categorized into 4 groups

- Group 1: Cases with ARAS (46 cases) (33.82\%).

- Group 2: Cases with PAD (38 cases) (27.94\%).

- Group 3: Cases with CAA (40 cases) $(29.41 \%)$.

- Group 4: Cases with no significant extracoronary atherosclerosis (NO.ECA) (12 cases) $(8.82 \%)$.

Cases of combined stenosis in more than one territory were not included among the 136 cases evaluated in the present study.

Significant RAS as proven by duplex US were detected in 46 cases out of the 136 examined being the commonest extracoronary atherosclerosis $(33.82 \%)$. CAA was detected in $29.41 \%$. PAD was detected in $27.94 \%$. Age of the studied groups revealed insignificant differences. Gender: $80 \%$ were males in CAA. Smoking was significantly elevated in the RAS group (73.9\%), PAD

MANSOURA MEDICAL JOURNAL 
$(63.2 \%)$ and $37.5 \%$ in CAA. The maximum WC was in the group of CAA $(120 \pm 10.5 \mathrm{~cm})$ and revealed higher significant values in comparison to the group of RAS and PAD. TIA was common only in CAA. The highest prevalence of intermittent claudication (52.6\%) was in the group of $P A D$ and the $A B I$ was lowest $(0.76 \pm 0.2)$ also in the group of $P A D$. FPG was significantly higher in RAS, PAD. The post $75 \mathrm{gm}$ plasma glucose was significantly higher in RAS, PAD and CAA groups in relation to ECA- control group. Significant dyslipidemia was detected in $65.2 \%$ of cases of RAS. Serum potassium was lowest in the group of RAS. Cases with $>20 \%$ significant rise of serum creatinine was detected in RAS group alone and insignificant rise in CAA and PAD. Positive captopril rise of $\mathrm{s}$. creatinine was highest in the group of RAS (34.7\%). It was higher than in the group of CAAD $(25 \%)$ than in the group of PAD (21.05\%).

Risk factors revealed significant elevation of blood glucose, smoking in all the ECAD. Dyslipidemia and
HTN were significantly elevated in RAS. Male gender and WC showed specific higher levels in CAA.

$A B I$ were $0.9 \pm 0.1$ in RAS, 0.86 in $\mathrm{CAA}$ and was $0.76 \pm 0.2$ in PAD and was $1.1 \pm 0.2$ in the non extracoronary group. Bruit was not significantly detected in any group.

Comparing the 4 studied groups as regards BP, plasma glucose revealed insignificant difference but SBP and DBP and smoking were significantly higher in the RAS group. Captopril induced renal impairment were significantly higher in the group of RAS.

The ECG results demonstrated LVH in RAS group only, significant arrhythmias and ischemia were not detected. Echocardiography: EF was significantly lower in RAS followed by CAA and PAD. Diastolic dysfunction grade I was observed in all the studied groups, while grade II was evident in $26.08 \%$ of cases of RAS only, while grade III diastolic dysfunction was not significantly evident in any group. 
Table (1): Demography, some clinical and risk factors of the studied groups.

\begin{tabular}{|c|c|c|c|c|c|c|c|c|c|c|}
\hline Parameter & $\begin{array}{c}\text { Group } 1 \\
\text { RAS } \\
\text { (46 cases) }\end{array}$ & $\begin{array}{c}\text { Group 2 } \\
\text { PAD } \\
\text { (38 cases) }\end{array}$ & $\begin{array}{c}\text { Group } 3 \\
\text { CAA } \\
\text { (40 cases) }\end{array}$ & $\begin{array}{c}\text { Group } 4 \\
\text { No ECA } \\
\text { control } \\
\text { (12 cases) }\end{array}$ & P1-2 & P1-3 & P1-4 & P2-3 & P2-4 & P3-4 \\
\hline $\begin{array}{l}\text { Age (years) } \\
\text { (Mean } 5 D D)\end{array}$ & $64.6 \pm 8.2$ & $62.1 \pm 5.6$ & $64.4 \pm 5.5$ & $61.1 \pm 5.5$ & 0.102 & 0.893 & 0.085 & 0.071 & 0.587 & 0.074 \\
\hline $\begin{array}{l}\text { Gender M/F } \\
\mathrm{M} \% \\
\mathrm{~F} \%\end{array}$ & $\begin{array}{l}26,20 \\
56.5 \% \\
43.5 \%\end{array}$ & $\begin{array}{l}21 / 17 \\
55.2 \% \\
54.8 \%\end{array}$ & $\begin{array}{l}32 / 8 \\
80 \% \\
20 \%\end{array}$ & $\begin{array}{l}6 / 6 \\
50 \% \\
50 \%\end{array}$ & 0.908 & 0.021 & 0.688 & 0.02 & 0.752 & 0.041 \\
\hline $\begin{array}{l}\text { Smoking - Present } \\
\text { Smoker"rok } \\
\text { Non smoker \% }\end{array}$ & $\begin{array}{l}34 / 46 \\
73.9 \% \\
26.1 \%\end{array}$ & $\begin{array}{l}24 / 38 \\
63.2 \% \\
36.8 \%\end{array}$ & $\begin{array}{l}15 / 40 \\
37.5 \% \\
62.5 \%\end{array}$ & $\begin{array}{c}1 / 12 \\
8.3 \% \\
91.7 \%\end{array}$ & 0.291 & $<0.001$ & $<0.001$ & 0.02 & 0.001 & 0.043 \\
\hline $\begin{array}{l}\text { Waist Cir. (WC) } \\
(\mathrm{cm})(\text { Mean } \pm \text { SD) }\end{array}$ & $113 \pm 10.1$ & $115 \pm 10.1$ & $120 \pm 10.5$ & $98 \pm 12.1$ & 0.368 & 0.002 & $<0.001$ & 0.035 & $<0.001$ & $<0.001$ \\
\hline SBP(Mean $\leq S D)$ & $165 \pm 6.7$ & $161 \pm 6.1$ & $162 \pm 6.9$ & $145 \pm 10.1$ & 0.005 & 0.044 & $<0.001$ & 0.499 & $<0.001$ & $<0.001$ \\
\hline DBP(Mean=S) & $110 \pm 5.5$ & $105 \pm 8.8$ & $105 \pm 10.1$ & $95 \pm 9.8$ & 0.003 & 0.006 & $<0.001$ & $\mathrm{~T}$ & 0.002 & 0.003 \\
\hline $\begin{array}{l}\text { Irans. Isch. } \\
\text { Attack(TIA) } \\
- \text { - Present \% } \\
\text {-Absent \% }\end{array}$ & $\begin{array}{c}2 / 46 \\
(4.3 \%) \\
95.7 \%\end{array}$ & $\begin{array}{c}2 / 38 \\
(5.3 \%) \\
94.7 \%\end{array}$ & $\begin{array}{l}11 / 40 \\
(7.5 \%) \\
72.5 \%\end{array}$ & $\begin{array}{c}0 / 12(0 \%) \\
100 \%\end{array}$ & 0.845 & 0.002 & 0.466 & 0.008 & 0.422 & 0.427 \\
\hline $\begin{array}{l}\text { No. of cases with } \\
\text { intemitent } \\
\text { claudication }\end{array}$ & $\begin{array}{l}6 \% 46 \\
13 \%\end{array}$ & $\begin{array}{l}20138 \\
52.6 \%\end{array}$ & $\begin{array}{l}6.40 \\
15 \%\end{array}$ & $\begin{array}{l}0 / 12 \\
0 \%\end{array}$ & $<0.001$ & 0.795 & 0.19 & $<0.001$ & 0.001 & 0.157 \\
\hline $\begin{array}{l}\text { ABI } \\
\text { (Mean } \pm \text { SD) }\end{array}$ & $0.9 \pm 0.1$ & $0.76 \pm 0.2$ & $0.86 \pm 0.1$ & $1.1 \pm 0.2$ & $<0.001$ & 0.004 & 8.001 & 0.006 & $<0.001$ & $<0.001$ \\
\hline
\end{tabular}

Table (2): Biochemical characteristic of the studied groups.

\begin{tabular}{|c|c|c|c|c|c|c|c|c|c|c|}
\hline $\begin{array}{l}\text { Paramter } \\
\text { (MeansSD) }\end{array}$ & $\begin{array}{l}\text { Group I } \\
\text { RAS } \\
\text { (46 cases) }\end{array}$ & $\begin{array}{l}\text { Group 2 } \\
\text { PAD } \\
\text { (38 cases) }\end{array}$ & $\begin{array}{c}\text { Group } 3 \\
\text { CAA } \\
(40 \text { cases })\end{array}$ & $\begin{array}{c}\text { Group } 4 \\
\text { No ECA } \\
\text { control } \\
(12 \text { cases) }\end{array}$ & $\frac{1}{P 1-2}$ & P1-3 & Pl-4 & P2:-3 & P2-4 & P3-4 \\
\hline FPG mgm $\%$ & $105 \pm 2.1$ & $106 \pm 3.1$ & $104 \pm 6.1$ & $92 \pm 2.1$ & 0.941 & 0.331 & $<0.001$ & 0.069 & $<0.001$ & $<0.001$ \\
\hline $\begin{array}{l}\text { Two hours post } \\
75 \mathrm{gm} \\
\mathrm{mgm} \%\end{array}$ & $153.2 \pm 4.2$ & \begin{tabular}{l|l|l}
$154.3+5.1$ \\
\end{tabular} & $154.7 \pm 3.8$ & $145.1 \pm 5.1$ & 0.29 & 0.08 & $<0.001$ & 0.696 & $<0.001$ & $<0.001$ \\
\hline $\begin{array}{l}\text { S.Cholesterol mg/ } \\
\text { dl }\end{array}$ & $188.1 \pm 10.1$ & $160.2 \pm 8.1$ & $158 \pm 2.1$ & $155 \pm 5.1$ & $<0.001$ & $<0.001$ & $<0.001$ & 0.108 & 0.011 & 0.052 \\
\hline TG $\mathrm{mg} / \mathrm{dl}$ & $180.2 \pm 8.1$ & $1770.3 \pm 10.1$ & $165.7 \pm 10.5$ & $130.1 \pm 8.1$ & $\frac{0.001}{2}$ & $<0.001$ & $<0.001$ & 0.059 & $<0.001$ & $<0.001$ \\
\hline HIDLcl mg dI & $35.2 \pm 3.1$ & $37.1 \pm 3.2$ & $36.7 \pm 2.1$ & $40.6 \pm 2.2$ & 0.007 & 0.009 & 20.001 & 0.518 & र. & 0.001 \\
\hline LDLCImg dI & $110.2 \pm 5.1$ & $107.3 \pm 4.1$ & $706.8 \pm 4.2$ & $99.9 \pm 3.11$ & 0.004 & 0.001 & $<0.001$ & 0.596 & <0.001 & <.001 \\
\hline $\begin{array}{l}\text { To. of cases with } \\
\text { significant } \\
\text { dyslipideamia }\end{array}$ & $\begin{array}{l}30 \\
65.2 \%\end{array}$ & $\begin{array}{l}10 \\
26.3 \%\end{array}$ & $\begin{array}{l}12 \\
30 \%\end{array}$ & $\frac{2}{16.6 \%}$ & $80.00 T$ & 0.001 & ४0.001 & 0.719 & 0.495 & 0.365 \\
\hline $\begin{array}{l}\text { No. of cases with } \\
\text { hypokalaamia } \mathrm{s} \text {. } \\
\mathrm{K}<3 \mathrm{meq} / \mathrm{L}\end{array}$ & $\begin{array}{l}24 \\
52.1 \%\end{array}$ & $\begin{array}{r}8 \\
21.1 \%\end{array}$ & $\begin{array}{l}10 \\
25 \%\end{array}$ & $\begin{array}{c}0 \\
0 \%\end{array}$ & 0.003 & 0.011 & 0.001 & 0.681 & 0.086 & 0.056 \\
\hline $\begin{array}{l}\text { No. of cases with } \\
\text { rise S. Creatinine } \\
>20 \% \text { with ACEI }\end{array}$ & $\begin{array}{l}16 \\
34.7 \%\end{array}$ & $\begin{array}{c}8 \\
21.05 \%\end{array}$ & $\begin{array}{l}10 \\
25 \%\end{array}$ & $\begin{array}{l}0 \\
0 \%\end{array}$ & 0.016 & 0.327 & 0.017 & 0.681 & 0.086 & 0.056 \\
\hline
\end{tabular}

MANSOURA MEDICAL JOURNAL 
Table (3): ECG, echocardiography findings of the studied groups.

\begin{tabular}{|c|c|c|c|c|c|c|c|c|c|c|}
\hline Parameter & $\begin{array}{c}\text { Group 1 } \\
\text { RAS } \\
\text { (46 cases) }\end{array}$ & $\begin{array}{l}\text { Group 2 } \\
\text { PAD } \\
\text { (38 cases) }\end{array}$ & $\begin{array}{c}\text { Group } 3 \\
\text { CAA } \\
\text { (40 cases) }\end{array}$ & $\begin{array}{c}\text { Group 4 } 10 \\
\text { ECA } \\
\text { control } \\
\text { (12 cases) }\end{array}$ & PI-2 & PI-3 & P1-4 & P2-3 & $72-4$ & P3-4 \\
\hline $\begin{array}{l}\text { ECG } \\
\text {-LVH } \\
\text { - Arrhythmia } \\
\text { - Ischemia }\end{array}$ & $\begin{array}{c}12 / 46(26.08 \%) \\
0 / 46(0 \%) \\
10 / 46(21.73 \%)\end{array}$ & $\begin{array}{c}1 / 38(2.63 \%) \\
0 / 38(0 \%) \\
6 / 38(15.78 \%)\end{array}$ & $\begin{array}{l}2 / 40(5 \%) \\
0 / 40(0 \%) \\
8 / 40(20 \%)\end{array}$ & $\begin{array}{c}0 / 12(0 \%) \\
0 / 12(0 \%) \\
2 / 12(8.33 \%)\end{array}$ & 0.492 & 0.844 & $\begin{array}{l}0.04 \\
0.701\end{array}$ & 0.630 & $\begin{array}{l}0.574 \\
0.942\end{array}$ & $\begin{array}{l}0.434 \\
0.799\end{array}$ \\
\hline$\overline{\mathrm{EF}}$ & $50.4 \pm 3.1$ & $56.3 \pm 4.2$ & $55.3+5.1$ & $60.2 \pm 4.2$ & $<0.001$ & $<0.001$ & $<0.001$ & 0.970 & 0.007 & 0.001 \\
\hline 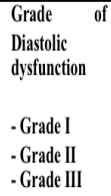 & $\begin{array}{c}31 / 46(67.39 \%) \\
12 / 46(26.08 \%) \\
3 / 46(6.52 \%)\end{array}$ & $\begin{array}{c}36 / 38(94.73 \%) \\
1 / 38(2.63 \%) \\
1 / 38(2.63 \%)\end{array}$ & $\begin{array}{l}38 / 40(95 \%) \\
1 / 40(2.5 \%) \\
1 / 40(2.5 \%)\end{array}$ & $\begin{array}{l}3 / 12(25 \%) \\
0 / 12(0 \%) \\
0 / 12(0 \%)\end{array}$ & $\begin{array}{l}0.002 \\
0.003 \\
0.407\end{array}$ & $\begin{array}{l}0.001 \\
0.002 \\
0.379\end{array}$ & $\begin{array}{l}0.008 \\
0.048 \\
0.367\end{array}$ & $\begin{array}{l}0.958 \\
0.970 \\
0.970\end{array}$ & $\begin{array}{l}<0.001 \\
0.574 \\
0.574\end{array}$ & $\begin{array}{l}<0.001 \\
0.583 \\
0.583\end{array}$ \\
\hline
\end{tabular}

\section{DISCUSSION}

The primary aim of the study was to evaluate the magnitude of extracoronary ischemia stressing on ARAS, CAA and PAD in patients with proven $C A D$ and to identify the diagnostic role of non- invasive approach.

Diagnosing ischemia in extracoronary territories is a bit difficult and needs a high index of clinical suspicion. Diagnosis of ARAS as early as possible is mandatory because meaningful recovery of kidney function is limited once renal fibrosis is established (8). Although it is stated that ARAS is under diagnosed yet in the present study clinically, there was significant elevation in SBP, diastolic BP and significant captopril- inVol. 42, No. 1 \& 2 Jan. \& April, 2013 duced renal impairment together with significant dyslipidimia and hypokalemia. Tobe and coworkers (2007) (5) considered that hypokalemia with HTN are among the clinical clues to suggest ARVD.

Persistent HTN, smoking and dyslipidimia are common in RAS. EI Fiky and Saleh (2001) (16) found no statistical significant difference between patients with and those without ARVD as regards age, sex, DM. In our study and of El Fiky and Saleh 2001 (16) smoking was frequently associated with RAS. The present results are in agreement with Dzielinska et al (2007) (17) and Salehi et al (2011) (18) who reported that traditional risk factors have a limited potential for predicting RAS. 
All groups revealed significant lowering of $\mathrm{ABI}$. This is in agreement with Fishbane et al (1995) (19) and Newman et al (1991) (20) and is confirmatory to Xie et al 2012(10) who found that $A B I$ is a valuable predictive index of midrange to severe ARAS. Newman et al (1999) (20) demonstrated that $A B I$ is not only a marker for diagnosing $P A D$, but also for generalized atherosclerotic disease.

In the present study RAS was present in $33.82 \%$. This is lower than that reported by El Fiky and Saleh (2001) (16) who had reported $59.1 \%$, but is higher to that reported by Vetrovec et al (1998) (21) in hypertensive patients with $C A D$ undergoing coronary angiography (20\%). Our results on RAS are in agreement with the finding of Harding et al dating to 1992 (22) in patients undergoning cardiac catheterization (30\%) and are confirmatory to those of Cianci et al (2012) (23), who found that up to $50 \%$ of patients with diffuse atherosclerosis have ARVD.

In the present study extracoronary atherosclerotic affection was detected in $91.18 \%$ and in only $8.82 \%$ of the studied cases there was no significant extracoronary affection. Przewlocki et al (2009) (2) detected significant atherosclerosis in extracoronary arterial territories in more than one third (36\%) of the patients with documented CAD.

Screening patients for RAS can be achieved by a variety of noninvasive methods, each has its merits and disadvantages. The renal duplex as performed in the present work has the advantage of providing anatomic and functional data (16).

Duplex scanning has been applied widely to assess the extracranial carotid arteries where it has become the non invasive investigation of choice. Conventional angiography although is the standarad method for determining the presence of RAS, yet the invasiveness and technical difficulties make it a less favourable scanning modality for RAS (24).

Duplex renal artery scanning was the method adopted in the present study and the presence of one or more of the accepted six abnormalities reported by Soulez et al (2001) (15) was considered indicative for the presence of RAS. The present results are in line with Coen et al (2003) (25) who concluded that col- 
our duplex ultrasonography is a valid method of investigating population at risk of RAS.

The present finding are confirmatory to $\mathrm{YY}$ and coworkers (2010) (11), who concluded that RA duplex scanning might still be the diagnostic procedure for scanning suspected patients, because it is inexpensive, convenient, capable to detect severity and avoid the dangers of contrast induced nephropathy.

Salehi et al (2011) (18) after evaluating the relationship between distribution of lesions in coronary artery tree and ARAS by performing simultaneous renal angiography following coronary angiography found RAS in $26.2 \%$ and CAD in $69.2 \%$. The present finding of RAS in $33.82 \%$ of our cases by RA duplex could be related to difference in the studied cases being older in the present study (66.2 \pm 6.8 years) and inclusion of any atherosclerotic narrowing $\geq 50 \%$ and on the whole the conclusion of Salehi et al (2011) (18) of simultaneous renal angiography following coronary angiography may be justified. Park et al (2010) (26) recommended the use of preoperative angiography for RAS as a routine test before
CABG.

Systemic atherosclerosis was detected in any of the three examined vascular territories. This is in agreement with Przewlocki et al (2009) (2), Rapezzi and Gallo (2010) (27) who stated that atherosclerosis is a polydistrectual disease. Also Badr et al (1999) (28) proved clinically and by duplex scanning that carotid and lower limb arterial disease are associated with a significant percentage of ARAS.

\section{CONCLUSION}

Extracoronary atherosclerosis is common in CAD and cases of CAD should be considered as a polyvascular problem as CAD is not a single atherosclerotic medical problem, but is a member of the gloomy orchestra of atherosclerosis. Early screening for RAS, CA stenosis and/or PAD has to be meticulously undertaken to save CAD patients not only from CV effects but also to maintain their renal, cerebral and limb vitality.

\section{REFERENCES}

1- ACC/AHA (2006) : guidelines for the management of patients with peripheral Arterial disease (lower extremity, 
renal, mesenteric, and abdominal aortic). Am Coll Cardiol J.; 47: 1239-312.

\section{2- Przewlocki T, Kablak-Ziembicka}

A, Kozanecki A, Rzeznik

$D$, Pieniazek $P$, Musialek

P, Piskorz A, Sokolowski

A, Roslawiecka A, Tracz W. (2009) : Polyvascular extracoronary atherosclerotic disease in patients with coronary artery disease. Kardiol Pol. Aug;67 (8A):978-84.

3- Chrysochou C, Kalra PA. (2010) : Atherosclerotic renovascular disease and the heart. J Ren Care. May;36 Suppl 1:146-53.

4- Bax L, Woittiez AJ, Kouwenberg HJ, et al. (2009) : Stent placement in patients with atherosclerotic renal artery stenosis and impaired renal function: a randomized trial. Ann Intern Med J.; 150: 840-8.

5- Sheldon W Tobe, M Atri, N Perkins, $R$ Pugash and Chaim M Bell. (2007) : Re- nal Athersosclerotic reVascularization Evaluation (RAVE Study) BMC Nephrology, 8:4. 1-8.

6- Tami L, Mc Eldery M, Al- Adli. (1995) : Renal artery stenosis presenting as crescendo angina pectoris. Catheterization and cardiovascular diagnosis.; 35: 252- 256.

7- Uwe Schwarzwälder, Michael Hauk and Thomas Zeller. (2009) : RADAR - A randomised, multi-centre, prospective study comparing best medical treatment versus best medical treatment plus renal artery stenting in patients with haemodynamically relevant atherosclerotic renal artery stenosis.Trials, 10:60 http:/ /www. trialsjournal. com/ content/10/1/60 1-12.

8-Textor SC, Lerman L. (2010) : Renovascular hypertension and ischemic nephropathy. Am J Hypertens. Nov;23 (11):1159-69. Epub Sep 23.

MANSOURA MEDICAL JOURNAL 
9- Gupta D, Chaudhary K, Nistala

R. (2010) : Stenting renal artery stenosis: what is the fuss all about? Rev Recent Clin Trials. Jan; 5 (1):28-34 .

10- Xie $Y Q$, Zhang $P$, Deng HB. (2012) : Ankle brachial index is a valuable index of the severity of atherosclerotic renal artery stenosis. Scand J Urol Nephrol. Jan 18.

11- Ng YY, Shen SH, Wang HK, Tseng HS, Lee RC, Wu SC. (2010) : Magnetic resonance angiography and Doppler scanning for detecting atherosclerotic renal artery stenosis. J Chin Med Assoc. Jun; 73 (6):300-7.

12- Chobanian AV, Bakris GL, Black HR. (2003) : Seventh Report of the Joint National Committee on Prevention, Detection and Treatment of High Blood Pressure. Hypertension; 42 (6): 1206-1252.
13- The American Diabetes Association. (1998) : Clinical practice recommendations; 21(1), S23.

14- The expert panel. (1993) : Summary of the second report of the national cholesterol education program NCEP expert panel on detection, evaluation and treatment of high blood cholesterol in adults (adult treatment panel II). JAMA; 269: 3015- 3023.

15- Soulez G, Oliva V, Turpin S, Imaging of renovascular hypertension. (2000) : Respective values of renal scintigraphy, Renal Doppler US, MR Angiography. Graphics; 20: 1355- 1368.

16- EI Fiky A and Saleh M. (2001) : Renal artery stenosis in patients with ischemic heart disease: Prevalence, role of renal duplex and coronary correlates. Egypt Heart J. 53 (4): 438-444.

17- Dzielinska Z, Januszewicz A, Demkow M, et al. (2007) : 
Cardiovascular risk factors in hypertensive patients with coronary artery disease and coexisting renal artery stenosis. Hypertens J.; 25:663-70.

18- Salehi N, Firouzi A, Gholoobi A, Shakerian F, Sanati HR, Ahmadabadi MN, Moradi M. (2011) : Relationship between distribution of coronary artery lesions and renal artery stenosis in patients undergoing simultaneous coronary and renal angiography. Clin Med Insights Cardiol. Mar 20; 5:35-40.

19- Fishbane S, Youn S, Kowalski EJ, Frei GL. (1995) : Ankle-arm blood pressure index as a marker for atherosclerotic vacular diseases in hemodialysis patients. Am J Kidney Dis 25: 3439.

20- Newman AB, Shemanski L, Manolio TA, Cushman M, Mittelmark M, Polak JF, Powe NR, Siscovick D. (1999) : Ankle-arm index as a predictor of cardiovas- cular disease and mortality in the Cardiovascular Health Study. The Cardiovascular Health Study Group. Arterioscler Thromb Vasc Biol 19: 538-545.

21- Vetrovec GW, Landwehr DM, Edwards VL. (1989) : Incidence of renal artery stenosis in hypertensive patients undergoing coronary angiography. J Intervent Cardiol; 2:69-76.

22- Harding $M$, Smith $S$, Hermiller J. (1992) : Renal artery stenosis: Prevalence and associated risk factors in patients undergoing routine cardiac catheterization $\mathrm{J}$ Am Soc Nephrol; 2: 160816.

23- Cianci R, Zuccalà A, Lucisano G, Barbano B, Martina P, Gigante A, Clemenzia G, Fuiano G. (2012) : Have We New Therapeutic Strategies in the Treatment of Renovascular Nephropathy? Curr Vasc Pharmacol. Jun 22.

24- Schmerk WB et al: (1994) : ReMANSOURA MEDICAL JOURNAL 
nal artery stenosis. Garding with image directed Doppler US. Evaluation of renal resistive index. Rdiology; 190: 785-790.

25- Giorgio Coen, Santo Calabria, Silvia Lai, Eleonora Moscaritolo, Italo Nofroni1, Giuseppe Ronga1, Michele Rossi, Guido Ventroni, Daniela Sardella, Michele Ferrannini, Alvaro Zaccaria and Rosario Cianci. (2003) : Atherosclerotic ischemic renal disease. Diagnosis and prevalence in an hypertensiveand/or uremic elderly population. BMC Nephrology, $\quad 4 \quad$ http:// www.biomedcentral.com/ 1471-2369/4/2 1-7.
26- Park KH, Lee HY, Lim C, Chung ES, Sung SW, Choi SI, Chun EJ. (2010) : Clinical impact of computerised tomographic angiography performed for preoperative evaluation before coronary artery bypass grafting. Eur J Cardiothorac Surg. Jun; 37(6): 1346-52.

27- Rapezzi C, Gallo P. (2010) : Atherosclerosis: a polidistrectual disease. G Ital Cardiol (Rome). Dec; 11(12 Suppl 3): 43S-48S.

28- Badr S, El Sheshawy F, Zagloul A, El Setiha M, Shabana N, Abdel Geleell A. (1999) : Renal artery stenosis associated with carotid and arterial limb disease.Tanta Medical J. 27 (1). 2575-2592. 